\title{
Implementation of Circuit Optimization Technique for Digital CMOS Comparator Using Parallel Prefix Tree Architecture
}

\author{
P. Ranjith ${ }^{1}$, P. Shankar Bharathi ${ }^{2}$, \\ ${ }^{I}$ PG Scholar, PG Department of Electrical Sciences, PA College of Engineering and Technology, Pollachi, \\ Coimbatore, Tamil Nadu, India, \\ ${ }^{2}$ Assistant Professor, Department of Electronics and Communication Engineering, PA College of Engineering \\ and Technology, Pollachi, Coimbatore, Tamil Nadu, India,
}

\begin{abstract}
The digital comparator using CMOS cells that adopts the parallel prefix tree architecture. This comparator begins from most significant bit towards bit-wise least significant bit when two compared bits are equal. Using circuit optimization technique it reduced by 642 transistors from total area of 768 and also maximum fan-in and fan-out drives of five and four respectively and $1.78 \mathrm{~mW}$ dynamic power dissipation for 16bit $(N)$ with 7 CMOS gate delay. The tanner EDA tool simulation for 16-bit is realized using 0.18- $\mu \mathrm{m}$ CMOS process technology with minimum supply voltage of $2.45 \mathrm{~V}$.
\end{abstract}

\section{INTRODUCTION}

The digital comparator place an important role which compares two input voltage and generates which is greater/lesser or equal.

\section{A. Types} signal.

1) Static Type: a combinational circuit which process input and generates its output without any global

Example: Prefix tree architecture binary comparator

2) Dynamic Type: a sequential circuit which process input by any initiative signals like clock, reset etc., and generates its output.

Example: Single clock-cycle binary comparator

\section{B. Applications}

Scientific computations, BIST, CPU argument comparison blocks.

\section{Existing Systems}

Dynamic type comparators will result in heavily loaded clock with number of gated transistors and also no power efficient

- Two phase clocking scheme needs large driver for a clock signal routing,

- Single phase clocking scheme results in clock skew and more delay and high power consumption.

Static type comparators slow high transistor count and more data dependencies

- Prefix tree structure perform only greater and lesser not for equality,

- Parallel prefix tree perform for all comparison result but takes more transistor count.

\section{A. Static type}

\section{IMPROVED PPT ARCHITECTURE}

A minor modification of [1] is done in implememtation structure proposed by Parhami et.al., by using XNOR with invertor Table 2.and reason for why moving to transmission gate for 2:1 multiplexer by other logic combinations Table 3.are realized here with tanner EDA simulation tool V.7.0.

The basic 8-bit comparison in Figure 1. States that bit-wise competition logic used here from MSB to LSB and stores the compared result in left and right OR network it results in the A or B greater or lesser if any one network is high or if both result not high then 2-input gate shows high that is both bit-width are equal. 


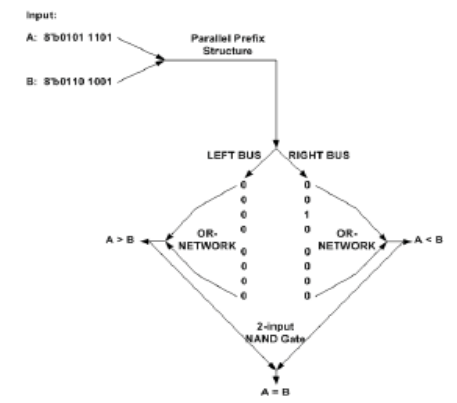

FIGURE 1. 8-B COMPARISON

\section{B. Modification done}

Common signals are to be design first that is invertor for all 16-bit obtained and also outputs of various CMOS cells also to be design paralleled and supplied to the logic gates. VLSI DSP architectures techniques like un-folding, re-timing concepts also applied here for circuit optimization.

\section{Model Used}

The improved system is realized as [2] using tanner EDA simulation tool V7.0 $1.25 \mu \mathrm{m}$ technology model file ml2_125.md with minimum supply voltage of $2.5 \mathrm{~V}$.

\section{Equations}

\section{E. Area, Power, Delay Report}

Compared to ppt this improved system reduce 126 transistors and total power consumption of $2.27 \mathrm{~mW}$ and it has total delay of 7 CMOS gate delay shown in Eqn. (2).
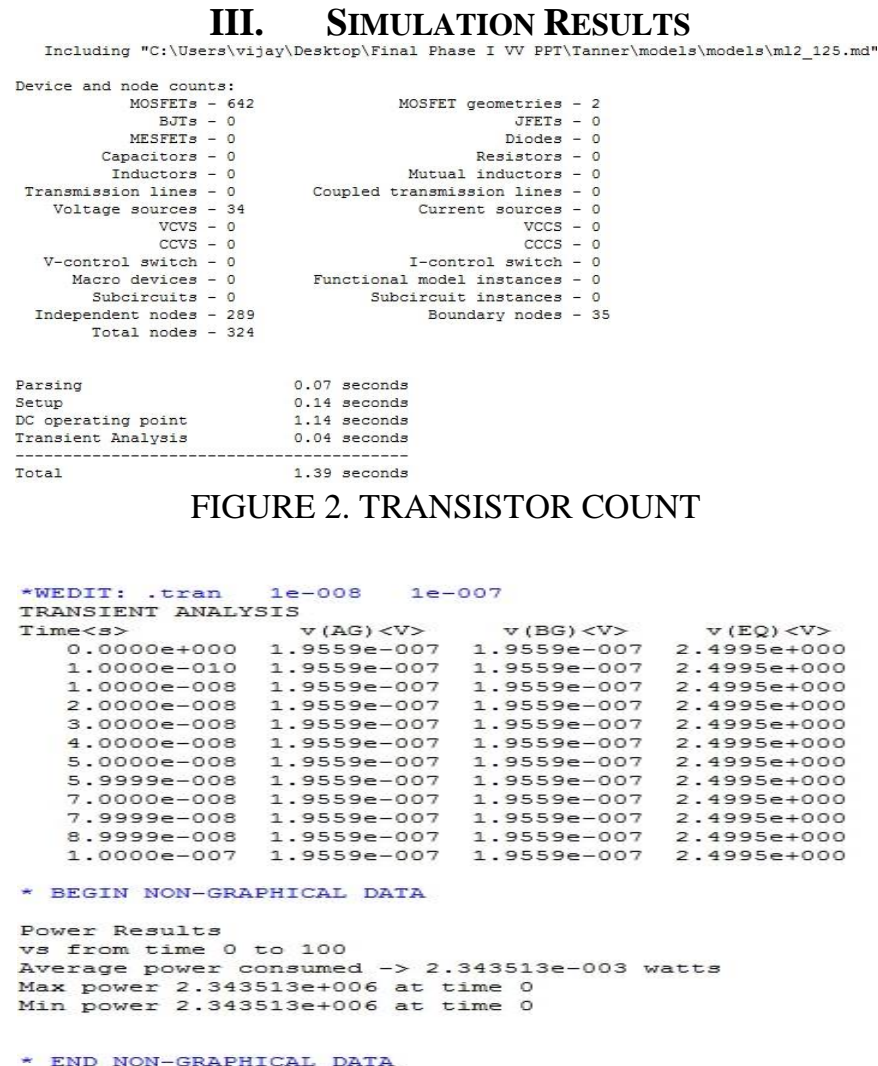

* end non-graphical data

FIGURE 3. POWER CONSUMPTION

\section{RESUlT COMPARISON}


TABLE 1. X-OR CELL DETAILS

\begin{tabular}{|c|c|c|}
\hline X-OR & X-OR & X-NOR WITH \\
\hline $\begin{array}{c}\text { TRANSISTOR } \\
\text { Carmim }\end{array}$ & 12 & 14 \\
\hline POWER & $1.73 \times 10^{-7} \mu \mathrm{W}$ & $2.07 \times 10^{-7} \mu \mathrm{W}$ \\
\hline
\end{tabular}

TABLE 2. 2:1 MUX DIFFERENT LOGIC COMPARISON

\begin{tabular}{|c|c|c|c|c|}
\hline 2:1 MUX & PASS & NAND & NOR & TG \\
\hline $\begin{array}{c}\text { TRANSISTOR } \\
\text { COUNT }\end{array}$ & 4 & 14 & 14 & 6 \\
\hline $\begin{array}{c}\text { POWER } \\
\text { DISSIPATION }\end{array}$ & $\begin{array}{c}4.13 \times 10^{-8} \\
\mu \mathrm{W}\end{array}$ & $\begin{array}{c}2.27 \times 10^{-7} \\
\mu \mathrm{W}\end{array}$ & $\begin{array}{c}2.03 \times 10^{-7} \\
\mu \mathrm{W}\end{array}$ & $\begin{array}{c}7.09 \times 10^{-8} \\
\mu \mathrm{W}\end{array}$ \\
\hline
\end{tabular}

TABLE 3. LOGIC SET REPRESENTATIONS

\begin{tabular}{|c|c|c|c|c|}
\hline CMOS CELLS & SET 1 & SET 2\&3 & SET 4 & SET 5 \\
\hline $\begin{array}{c}\text { MAX. FAN-IN } \\
\text { \& FAN-OUT }\end{array}$ & $2 / 4$ & $4 / 3$ & $5 / 1$ & $3 / 2$ \\
\hline $\begin{array}{c}\text { TRANSISTOR } \\
\text { COUNT }\end{array}$ & 14 & 8 & 20 & 12 \\
\hline POWER & $\begin{array}{c}2.07 \times 10^{-7} \\
\mu \mathrm{W}\end{array}$ & $\begin{array}{c}2.99 \times 10^{-8} \\
\mu \mathrm{W}\end{array}$ & $\begin{array}{c}2.24 \times 10^{-8} \\
\mu \mathrm{W}\end{array}$ & $\begin{array}{c}7.09 \times 10^{-8} \\
\mu \mathrm{W}\end{array}$ \\
\hline
\end{tabular}

TABLE 4. NO. OF CELLS COMPARISON

\begin{tabular}{|c|c|c|c|c|c|}
\hline 16-BIT & SET 1 & SET 2 & SET 3 & SET 4 & SET 5 \\
\hline IMPROVED & 16 & 3 & 3 & 16 & 16 \\
\hline EXIST & 16 & 4 & 4 & 16 & 16 \\
\hline
\end{tabular}

TABLE 5. NO. OF TRANSISTOR COUNT COMPARISON

\begin{tabular}{|c|c|c|}
\hline 16-BIT & IMPROVED & EXIST \\
\hline $\begin{array}{c}\text { TRANSISTOR } \\
\text { COUNT }\end{array}$ & 642 & 768 \\
\hline
\end{tabular}

TABLE 6. AREA AND POWER REPORT TABLE

\begin{tabular}{|c|c|}
\hline 16-BIT & $1.25 \mu \mathrm{m} 2.5 \mathrm{~V}$ \\
\hline $\begin{array}{c}\text { TRANSISTOR } \\
\text { COUNT }\end{array}$ & 642 \\
\hline $\begin{array}{c}\text { POWER } \\
\text { DISSIPATION }\end{array}$ & $2.27 \mathrm{~mW}$ \\
\hline
\end{tabular}

\section{CONClusion \& Future Work}

The architecture reduces power dissipation and total area consumed for 16-bit digital comparator than existing system. Simulation based analysis conclude that low power system and area consumption is less.

Future work will include circuit optimization like high speed zero detector, etc., to reduce power and delay and to implement the structure in $180 \& 150 \mathrm{~nm}$ CMOS and TSMC technology with minimum supplied voltage.

\section{REFERENCES}

[1] Saleh Abdel-Hafeez, Ann Gordon-Ross, and Behrooz Parhami, Life Fellow, IEEE, "Scalable Digital CMOS Comparator Using a Parallel Prefix Tree,” IEEE Transactions On Very Large Scale Integration (VLSI) Systems, vol. 21, Issue 11, pp. 1989-1998, November 2013.

[2] Anjuli, Satyajit Anand, "High-Speed 64-Bit Binary Comparator using Three Different Logic Styles,” International Journal of Scientific \& Engineering Research, Vol. 4, Issue 5, pp. 1076-1081, May 2013.

[3] Joo-Young Kim, and Hoi-Jun Yoo, "BCL for Compact Digital Comparator," IEEE Asian Solid-State Circuits Conference, pp. 5962, November 2007. 